\title{
Shallow Layer Destruction Law of Expansive Soil Slope under Rainfall and the Application of Geogrid Reinforcement
}

\author{
Guan-yi Chen $\mathbb{D}^{1,},{ }^{1,2}$ Peng He $\mathbb{D}^{3},,^{3}$ Gang Wang $\mathbb{D}^{3}$, Shang-qu Sun $\mathbb{D}^{3},{ }^{3}$ and Jie Xiao $\mathbb{}^{1}$ \\ ${ }^{1}$ School of Traffic \& Transportation Engineering, Changsha University of Science and Technology, Changsha, Hunan 410114, China \\ ${ }^{2}$ Guangdong Honggao Construction Group Co., LTD., Dongguan, Guangdong 523000, China \\ ${ }^{3}$ Shandong Provincial Key Laboratory of Civil Engineering Disaster Prevention and Mitigation, Shandong University of Science \\ and Technology, Qingdao, Shandong 266590, China
}

Correspondence should be addressed to Jie Xiao; xjxnn07820@qq.com

Received 4 November 2020; Accepted 4 June 2021; Published 9 July 2021

Academic Editor: Paolo Madonia

Copyright (c) 2021 Guan-yi Chen et al. This is an open access article distributed under the Creative Commons Attribution License, which permits unrestricted use, distribution, and reproduction in any medium, provided the original work is properly cited.

\begin{abstract}
A large number of instability cases and laboratory tests of expansive soil slopes show that its shallow layer destruction happens because of the insufficient shear strength under the usual action of low stress and repeated dry-wet cycles. We can obtain the strength nonlinear distribution law fitted by generalized power function based on a series of shear strength tests of expansive soil considering low stress and can construct the numerical model considering the nonlinear strength distribution by FISH, to realize the shear strength dynamic distribution with the vertical stress. Based on the numerical model, the whole-process contrastive analysis has been conducted on the stress field, the slip surface depth, and the seepage field of plain soil and reinforced expansive soil cut slope under different rainfall conditions. Besides, the mechanics characteristic of the geogrid under various design schemes has been compared and analyzed. A further explanation has been given for the expansive soil cut slope prone to shallow layer failure after rainfall and on the effect of geogrid reinforcement. The numerical results provide a reference for slope stability analysis in rainy expansive soil areas.
\end{abstract}

\section{Introduction}

Being regarded as the "cancer in engineering," expansive soils are found in more than 40 countries and regions in the world [1]. Expansive soil is very prone to collapse due to its unique expansibility, fissure, and overconsolidation [2]. Collapse destruction can happen even at a slope ratio of $1: 4 \sim 1: 6$.

Generally, the shallower burial depth of the expansive soil makes smaller overburden pressure and a greater influence of dry-wet cycles. More cracks would occur in the soil, causing more severe intensity attenuation [3]. Moreover, the conventional shear tests are conducted under high stress $(100,200$, 300 , and $400 \mathrm{kPa}$ or $50,100,200$, and $300 \mathrm{kPa}$ ) according to the specification. We adopt linear regression for the strength parameter values. The results, however, often differ significantly from reality. The most common failure mode of expansive soil slope is shallow layer slipping $[2,4,5]$. When the thickness of the sliding body is less than $1.5 \mathrm{~m}$, the vertical pressure of the sliding soil becomes less than $30 \mathrm{kPa}$. As the measured shear strength of the soil is often nonlinear [6-8], the strength parameters that match actual engineering conditions can be obtained only when conducting the shear test under low stress.

The action of water is another important external factor affecting the stability of expansive soil slopes, as many expansive soil slopes become unstable in the rainy season or after a heavy rainfall [9-14]. The influence of water on the expansive soil slopes can be analyzed by several aspects: firstly, the increase of water content will change the physical and mechanical properties of expansive soil significantly, mainly causing an increase in porosity, a decrease of intergranular coupling force, etc. Meanwhile, a large number of desiccation cracks occur in the shallow layer of the expansive soil slopes under the action of the atmospheric dry-wet cycle, and the cracks cause a large amount of rainwater infiltration, which results in a decrease or even loss of the matric suction, eventually leading to a decrease in the shear strength $[4,15-17]$. Moreover, some scholars have proposed that the influence of the current static and dynamic load on the slope stability 
should also be considered from the perspective of seepage force during rainfall infiltration $[14,18-20]$. In essence, expansive soil slope seepage, under rainfall, is a typical unsaturated soil seepage problem. Thus, the influence of multifield hydraulic coupling must be considered for the instability failure caused by rainfall in expansive soil slopes. At present, there are two ways to solve real scientific and engineering problems. In the first way, pure mathematical methods are used to derive analytical solutions $[21,22]$, while in the second, numerical methods are used to produce approximate numerical solutions $[23,24]$. During the rapid advancement of the emerging computational geoscience field, researchers have obtained many analytical solutions for complicated geoscientific problems, in which both temperature and pore-fluid flow (i.e., seepage flow) have been considered. Consequently, such advanced numerical methods can also be used to investigate the shallow layer destruction of expansive soil slopes under rainfall and geogrid reinforcement.

The conventional treatment methods for expansive soil areas were mostly "soil replacement" or "modification treatment," which not only caused a great waste of resources but also destroyed the ecological environment. The physicochemical reaction for chemical modification, in particular, will improve the conversion products in the soil greatly, resulting in the change of $\mathrm{pH}$, which will have a long-term negative impact on vegetation growth. Nowadays, more attention is paid to the harmony and protection of the ecological environment. Hence, future research on expansive soil should be focused on environment-friendly methods. Soil reinforcement, a mechanical means of stabilizing weak soil, involves the use of fibrous materials, which can be in the form of geosynthetics (geogrid, geotextile, geocomposite, and geonet) or randomly distributed fibers of natural or synthetic origin $[25,26]$. Many researchers have used geotechnical analysis software to simulate and optimize the flexible support of the expansive soil slopes and have achieved remarkable results in China [2, 27-29]. However, it is still necessary to further explore the failure mechanism of the expensive soil slope's shallow layer and the stress characteristics of geogrid under different rainfall conditions while also considering the nonlinear distribution of soil strength of expansive soil slopes.

In this paper, the strength nonlinear distribution law, fitted by a generalized power function, is obtained based on a series of shear strength tests of expansive soil. The numerical model considering the nonlinear strength distribution is constructed by FISH to realize the shear strength dynamic distribution with the vertical stress of the slope. Based on the numerical model, the whole-process contrastive analysis has been conducted on the stress field, the slip surface depth, and the seepage field of plain soil and reinforced expansive soil cut slopes under different rainfall conditions. Additionally, the mechanical characteristic of the geogrid surface under different design schemes is also analyzed.

\section{Shallow Layer Failure Model of Expansive Soil Slope}

It has been observed that the failure depth of expensive soil slopes is usually between $0.5 \mathrm{~m}$ and $2.0 \mathrm{~m}$ [30]. At these depths, the dry-wet cycle of the soil is significant due to the atmospheric effect, and the effective normal stresses are mostly between $5 \mathrm{kPa}$ and $35 \mathrm{kPa}$, much smaller than the vertical pressure $(50,100,200$, and $300 \mathrm{kPa})$ applied to the specimen in the conventional shear test. It is, however, inappropriate to analyze the slope stability using the conventional shear test strength parameters. Therefore, we carried out the strength shear test, considering the time of different dry-wet cycles under low-stress conditions, to obtain the shear strength parameters suitable for the effective normal stress on the slope sliding surface. The specific test and operating procedures are detailed in the literature [31]. The series shear test results show that the shear strength increases nonlinearly with the increase of vertical pressure, especially for the low-stress section, which can be well fitted by a generalized power function:

$$
\tau=S_{\mathrm{NL}}(\sigma \mid A, n, T) \equiv P_{a} A\left(\frac{\sigma}{P_{a}}+T\right)^{n} .
$$

Here, $P_{a}$ stands for atmospheric pressure, $\{A, n, T\}$ are nondimensional strength parameters, and $S_{\mathrm{NL}}(\sigma \mid A, n, T)$ is a nonlinear strength function. The notation $S_{\mathrm{NL}}(\sigma)=S_{\mathrm{NL}}$ $(\sigma \mid A, n, T)$ emphasizes the dependence of strength functions on their parameters. Particularly, $A$ is the scale parameter controlling the magnitude of shear strength, $T$ is a shifting parameter controlling the location of the envelope on the $\sigma$ axis $\left(t_{\mathrm{NL}}=P_{a} T\right.$ is the tensile strength associated with $S_{\mathrm{NL}}$ $(\sigma)=S_{\mathrm{NL}}(\sigma \mid A, n, T)$, with $T$ representing a nondimensional tensile strength), and $n$ controls the curvature of the envelope [7]. Here, $A>0,1 / 2 \leq n \leq 1, T \geq 0$. When $n=1$, $A=\tan \varphi$, and $T=\left(c / P_{a}\right) \tan \varphi$, Equation (1) becomes the expression of Mohr-Coulomb (MC) strength norm. Figure 1 shows the failure envelopes of the generalized power function in Equation (1).

2.1. Test Analysis of the Nonlinear Shear Strength. Almost all expansive soil slope failures are in the form of shallow layer slipping failure, and the overburden pressure of the soil above the slip surface is less than the value specified in the conventional shear test. The dry-wet cyclic shear test with loading has been carried out on undisturbed soil [7, 31, 32], revealing the effects of dry-wet cycles, especially of low stress, on the nonlinear shear strength of expansive soil. The test results are presented in Table 1. (Since the point of this work is the shallow layer destruction law of expansive soil slope under rainfall and application of geogrid reinforcement, here is a brief introduction of the shear strength of expansive soil under wet-dry cycles with loading. To make it easier to understand, some related studies are available for References [7, 31, 32].)

Table 1 shows nonlinear strength characterization parameters and conventional shear strength parameters, which indicates that the effect of a dry-wet cycle, with loading on shear strength, is significantly higher in the low-stress section than that for the high-stress section. It thus explains why the expansive soil slope that has just been excavated is usually very stable; the shallow layer damages happen during a certain rainfall period or after rainfall. The distribution 


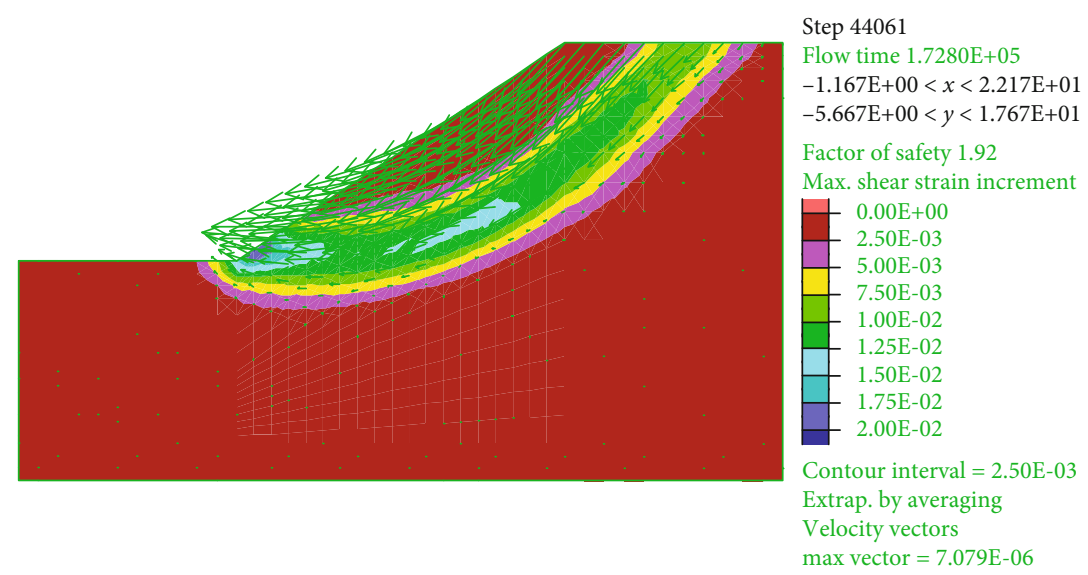

(a) Without support

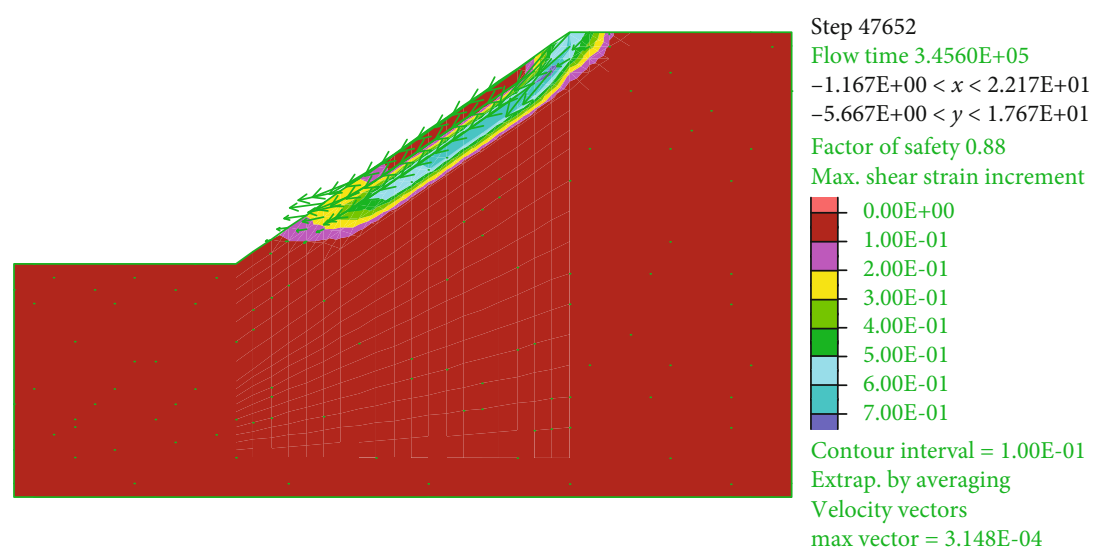

(b) With support

FIgURE 1: Comparison of shear strain increment for different calculation models.

TABLE 1: Undisturbed soil dry-wet cycles shear strength parameters with loading.

\begin{tabular}{lccccr}
\hline \multirow{2}{*}{ Wet/dry cycle number } & \multicolumn{3}{c}{ Dimensionless parameters } & Intercept of the fitted curve on $y$-axis & \multicolumn{2}{c}{$75-300(\mathrm{kPa})$} \\
& $A$ & $T$ & $N$ & 26.7 & 30.4 \\
\hline 0 & 0.5665 & 0.4617 & 0.9889 & 16.8 & 28.5 \\
2 & 0.6111 & 0.2535 & 0.9495 & 7.1 & 28.7 \\
4 & 0.6900 & 0.0724 & 0.8731 & 1.4 & 21.6 \\
6 & 0.7074 & 0.0094 & 0.8417 & 0.0 & 28.4 \\
8 & 0.7176 & 0.0000 & 0.8444 & 28.1 \\
\hline
\end{tabular}

parameter should also be considered in the stability analysis of the expansive soil slope to obtain a more reasonable simulation result.

\subsection{Construction of the Strength Nonlinear Distribution} Model. We construct a numerical model considering the nonlinear distribution of strength based on the results of the above soil shear strength test by adopting the generalized power function to fit the nonlinear strength formula and introducing it into FLAC2D by FISH. To verify the rationality of the numerical model of the expansive soil slope with nonlinear strength distribution, the conventional model and the nonlinear distribution model have been established, respectively, with rainfall intensity of $55 \mathrm{~mm} / \mathrm{d}$ and duration of $4 \mathrm{~d}$. The strength parameters in the conventional model are $c=30 \mathrm{kPa}, \varphi=20$; the fitting parameters in the contrastive model are $A=0.4691, n=0.8352$, and $T=$ 0.0352; other soil parameters are the same. In this way, a comparative analysis has been conducted on the effect of the nonlinear distribution of soil strength on the tability of slopes under rainfall infiltration. It must be noted that due to the limitation of using a commercial computer code (i.e., FLAC2D), the effect of chemical reactions is not considered in this study. 
TABLE 2: Expansive soil parameters of Nanyou Highway at K136+00-K136+370.

\begin{tabular}{lcccccc}
\hline $\begin{array}{l}\text { Ratio, } \\
G_{s}\end{array}$ & $\begin{array}{c}\text { Natural moisture } \\
\text { content }(\%)\end{array}$ & $\begin{array}{c}\text { Standard absorption moisture } \\
\text { content }(\%)\end{array}$ & $\begin{array}{c}\text { Free expansion } \\
\text { ratio }(\%)\end{array}$ & $\begin{array}{c}\text { Plasticity } \\
\text { index }(\%)\end{array}$ & $\begin{array}{c}\text { Plasticity limit } \\
(\%)\end{array}$ & $\begin{array}{c}\text { Liquid limit } \\
\left(\mathrm{m}^{2} / \mathrm{g}\right)\end{array}$ \\
\hline 2.71 & 30.34 & 6.3 & 57.5 & 39.8 & 31.5 & 71.2 \\
\hline
\end{tabular}

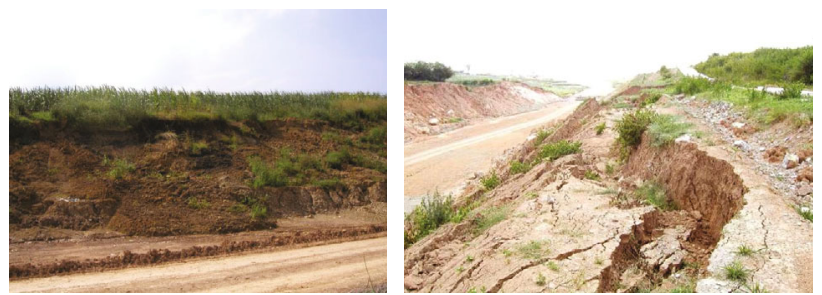

FIgURE 2: Collapse of expansive soil slopes.

TABLE 3: The parameters of geogrid and reinforced soil interface.

\begin{tabular}{lcccccc}
\hline $\begin{array}{l}\text { Geogrid } \\
\text { type }\end{array}$ & $\begin{array}{c}\text { Thickness } \\
(\mathrm{m})\end{array}$ & $\begin{array}{c}\text { Modulus of } \\
\text { elasticity (MPa) }\end{array}$ & $\begin{array}{c}\text { Interfacial shear } \\
\text { stiffness }(\mathrm{kN} / \mathrm{m})\end{array}$ & $\begin{array}{c}\text { Reinforcement } \\
\text { interval }(\mathrm{m})\end{array}$ & $\begin{array}{c}\text { Reinforcement } \\
\text { length }(\mathrm{m})\end{array}$ & $\begin{array}{c}\text { Interface } \\
\text { pseudocohesion } \\
(\mathrm{kPa})\end{array}$ \\
\hline RS 35PP & $5 E-4$ & 450 & $4.7 E 3$ & 0.5 & 3.5 & $\begin{array}{c}\text { Interface } \\
\text { pseudofriction } \\
\text { angle }\left({ }^{\circ}\right)\end{array}$ \\
\hline
\end{tabular}

Figure 1 shows the safety factor and shear strain increment distribution using the two models. It can be seen that the slope safety factor obtained by the conventional model is relatively high $\left(F^{\prime} \mathrm{S}=1.92\right)$, and the safety factor is low ( $F$ 's $=0.88$ ) on adopting the nonlinear strength parameters, in consistence with the engineering practice of the shallow layer collapse of the expansive soil slope.

\section{Comparative Analysis of the Geogrid Reinforcement Treatment under Rainfall Conditions}

3.1. Project Overview. Nanning-Youyiguan Expressway is an important part of the Hengkun Highway (G275). It connects directly to the No.1 Highway in Vietnam, with a total length of $220 \mathrm{~km}$. It receives an average annual rainfall of $1200 \mathrm{~mm}$ and undergoes a significant dry-wet cycle effect. Typical weathered residual gray expansive soil is found in the road section, and the soil parameters obtained by the laboratory test are shown in Table 2. As it is located in the hot and humid area of the south, the maximum daily rainfall exceeds $120 \mathrm{~mm}$ during the rainy season. Affected by the dry and wet circulation of the atmosphere, small collapse occurs in some slopes after several months of excavation (Figure 2). As the rainfall continues, severe sliding damages occur to 23 slopes in an expansive soil area along the Nanyou road.

3.2. Model Specification. We establish a plain soil cut slope (model I) and reinforced expansive soil cut slope (model II) based on the above research in Sections 2.1 and 2.2. The strength parameter values with 8 dry-wet cycles of undisturbed soil are used in model II, i.e., $A=0.4691, n=0.8352$, and $T=0.0352$. Other physical and mechanical parameters are listed in Table 2. The parameters of geogrid and reinforced soil interface are mentioned in Table 3.

The slope mode is based on the actual size of the expansive soil slope encountered in Nanyou road engineering. The cut slope has a height of $6 \mathrm{~m}$ and a slope ratio of $1: 1.5$. Under the action of the dry-wet cycle, fissures of the expansive soil slope develop randomly and form a network; as the rainwater enters, it flows along the fissures. In view of this, we use a stratification equivalent method to divide the expansive surface soil into three layers according to the degree of weathering, namely, the completely weathered layer, the weakly weathered layer, and the unweathered layer.

We set the strong weathering layer as $1.0 \mathrm{~m}$ thick, the weak weathering layer as $2.0 \mathrm{~m}$ thick, and the lower slope soil as the unweathered layer. The saturated permeability coefficients of the strong, weak, and unweathered layers have been set to be $2.3 \times 10^{-6} \mathrm{~m} / \mathrm{s}, 2.3 \times 10^{-7} \mathrm{~m} / \mathrm{s}$, and $2.3 \times 10^{-8} \mathrm{~m} / \mathrm{s}$, respectively. Provided that the groundwater is $1 \mathrm{~m}$ deep, the left and right sides of the model are pressure boundaries, i.e., the permeable boundaries; the bottom side is the seepage-free boundary. When the intensity of rainfall is less than the soil permeability coefficient, the slopes are treated as flow boundaries. Otherwise, they are calculated as boundaries of fixed water levels.

We set the rainfall intensity to be $55 \mathrm{~mm} / \mathrm{d}$ (converted to $6.32 \times 10^{-7} \mathrm{~m} / \mathrm{s}$ for calculation in FLAC2D) $[7,33,34]$. Generally, the expansive soil slope will not be destroyed under the condition of light rain or moderate rain (the rainfall intensity is $20 \sim 50 \mathrm{~mm} / \mathrm{d}$ ); hence, only hard rain condition has been discussed in this paper.

3.3. Contrastive Analysis of Reinforced and Unreinforced Expansive Soil. The changes of unreinforced soil and 

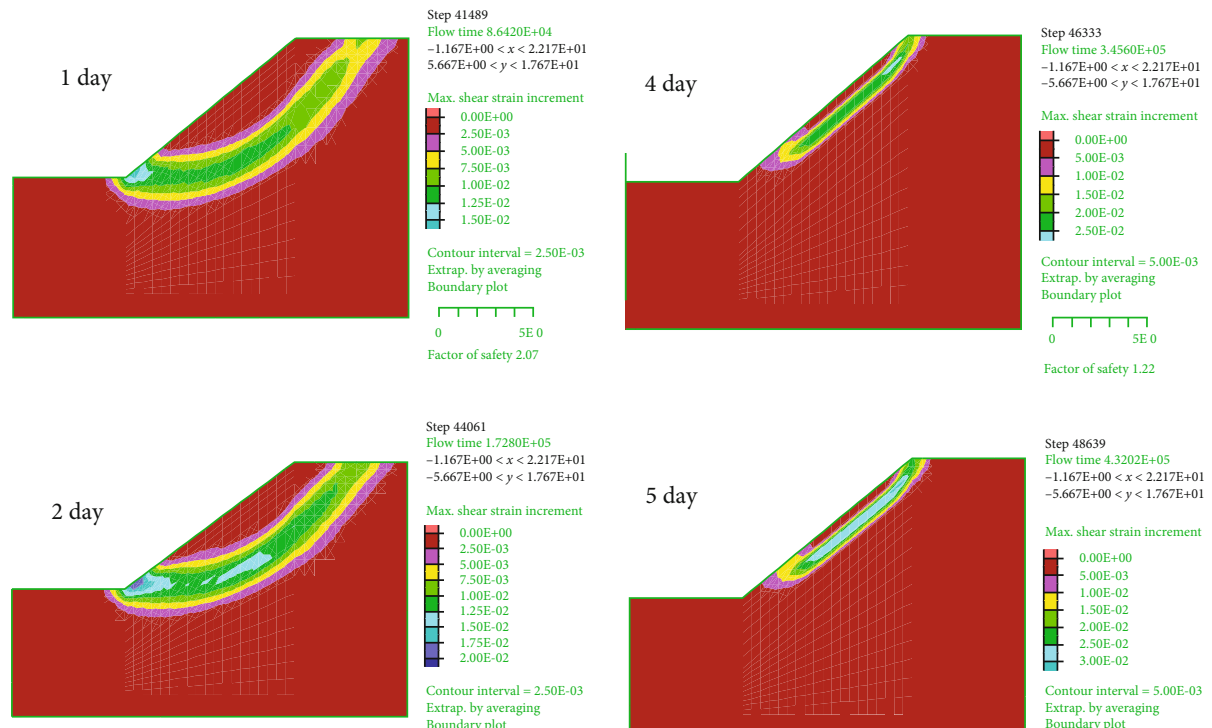

Step 44061

Flow time $1.7280 \mathrm{E}+05$
$-1.167 \mathrm{E}+00<x<2217 \mathrm{E}+01$
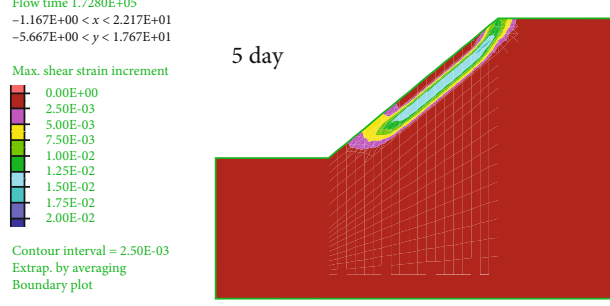

Step 4863

Flow time $4.3202 \mathrm{E}+05$ $-5.667 \mathrm{E}+00<y<1.767 \mathrm{E}+01$

$F^{0.00 \mathrm{E}+00}$

- $\begin{array}{r}1.00 \mathrm{E}-02 \\ 1.50 \mathrm{E}-02 \\ 2.00 \mathrm{E}-02\end{array}$

$\#^{2.50 \mathrm{E}-02}$

Extrap, by averaging

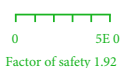

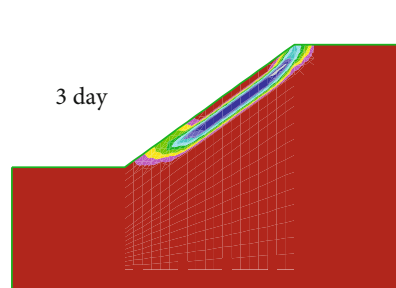

Step 46864

Flow time $2.5922 \mathrm{E}+05$
$-1.167 \mathrm{E}+00<x<2.217 \mathrm{E}+01$
$-5.667 \mathrm{E}+00<y<1.767 \mathrm{E}+01$

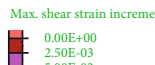



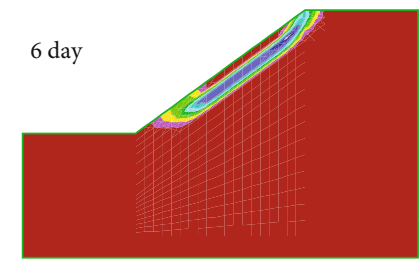

Step 54633

xtrap. by averaging

ता 11

tor of safety 1.08

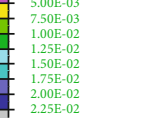

ontour interval $=2.50$

Extrap, by averaging
Boundary plot

ता Tा

$-1.167 \mathrm{E}+00<x<2217 \mathrm{E}+01$

$-5.667 \mathrm{E}+00<y<1.767 \mathrm{E}+01$

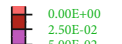

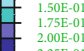

Contour interval $=2.50 \mathrm{E}-02$ Extrap. by averaging
Boundary plot

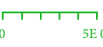

(a) Without support

Figure 3: Continued. 

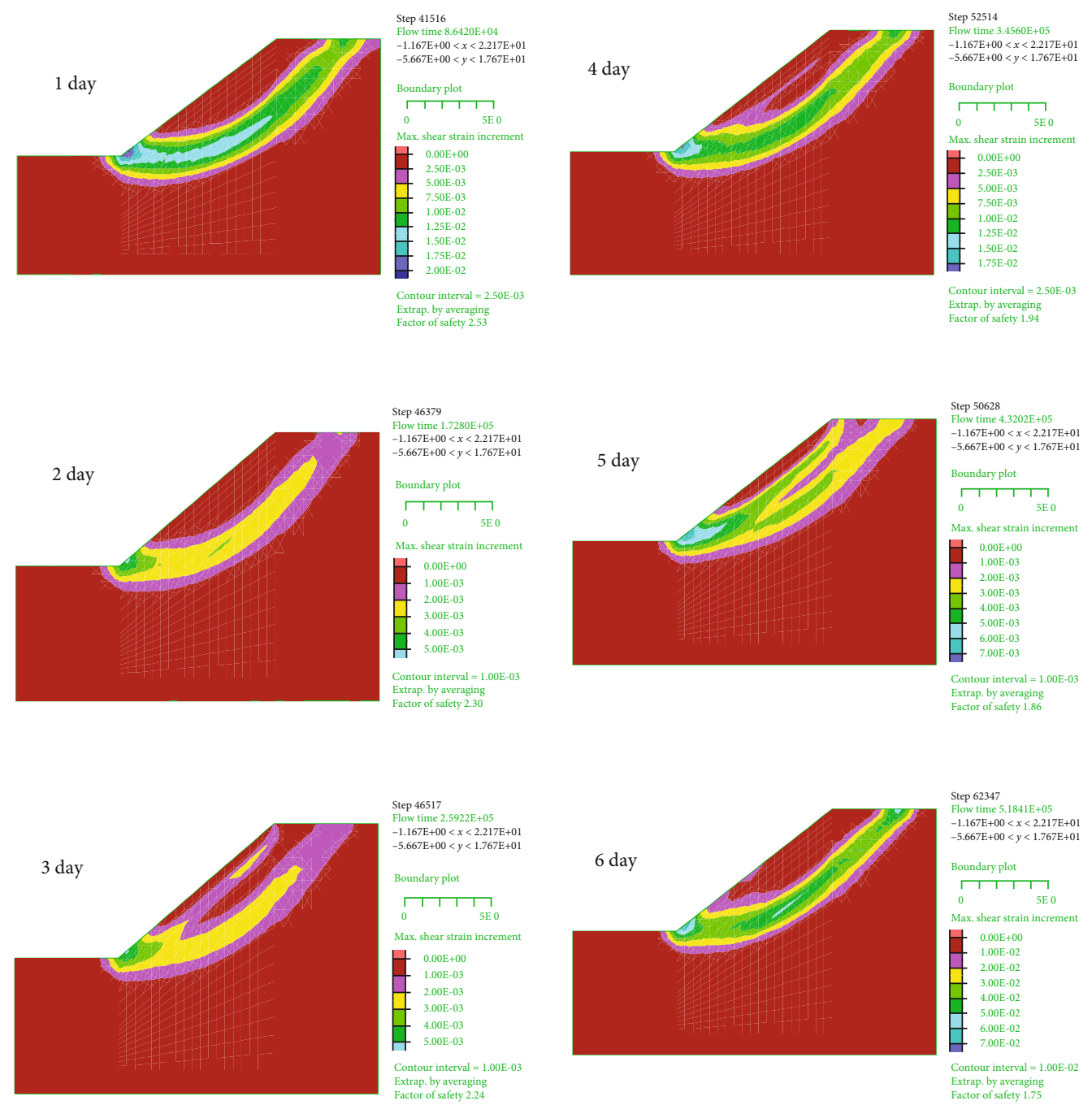

(b) With support

FIgURE 3: The shear strain increment of plain soil and reinforced expansive soil slope under different rainfall durations.

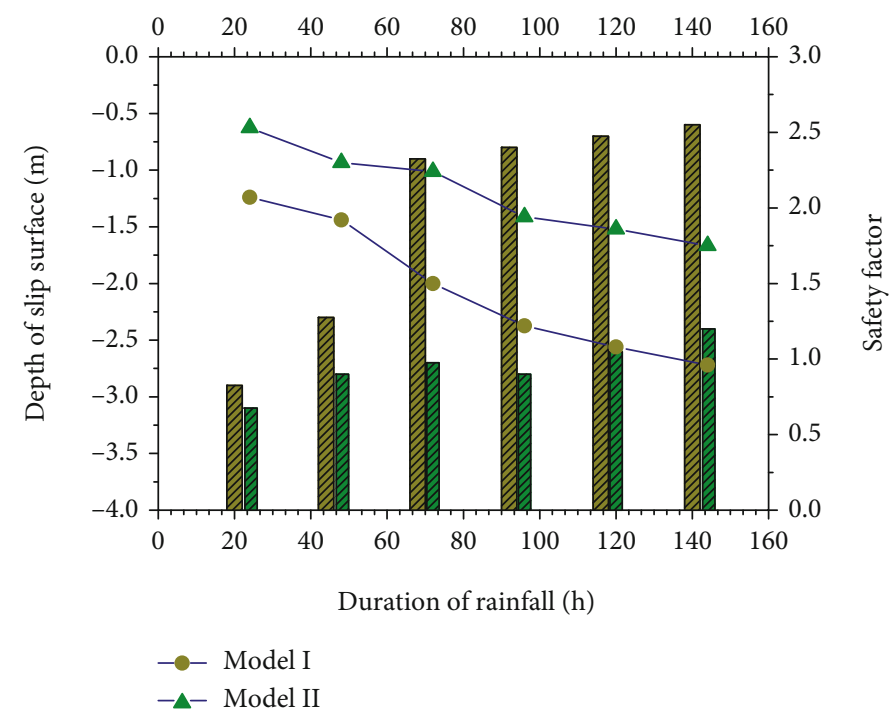

FIGURE 4: Comparison of the safety factor and slip surface depth between plain soil and reinforced expansive soil slope. 


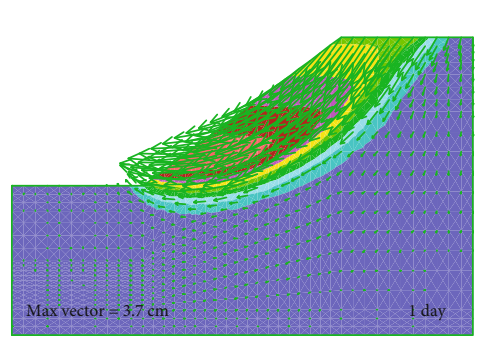

Step 41516

Flow time $8.6420 \mathrm{E}+04$

$-1.167 \mathrm{E}+00<x<2.217 \mathrm{E}+01$

-

$X$-displacement contour

$H^{-4.00 \mathrm{E}-02}$

$F_{-2.50 \mathrm{E}-02}^{-3.00 \mathrm{E}-02}$

$-2.00 \mathrm{E}-02$
$-1.50 \mathrm{E}-02$

$-1.00 \mathrm{E}-02$
$-5.00 \mathrm{E}-03$

$0.00 \mathrm{E}+00$

Contour interval $=5.00 \mathrm{E}-03$ Displacement vectors $\max$ vector $=4.433 \mathrm{E}-0$ $1 \mathrm{E}-1$

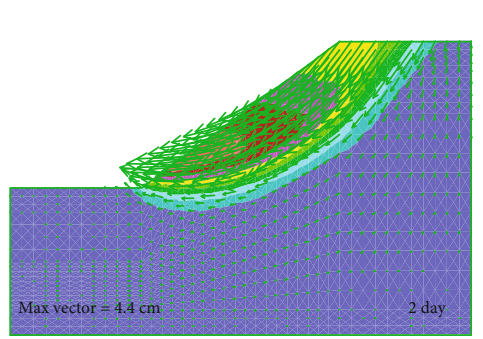

Step 44061

Flow time $1.7280 \mathrm{E}+05$

$-1.167 \mathrm{E}+00<x<2.217 \mathrm{E}+01$ $-5.667 \mathrm{E}+00<y<1.767 \mathrm{E}+01$

$X$-displacement contours

$-4.00 \mathrm{E}-02$
$-\quad-30 \mathrm{E}-02$

${ }^{-}-3.00 \mathrm{E}-02$

$-2.50 \mathrm{E}-02$
$-2.00 \mathrm{E}-02$
$-1.50 \mathrm{E}-02$

- $\begin{array}{r}-1.00 \mathrm{E}-02 \\ -5.00 \mathrm{E}-03\end{array}$

Contour interval $=5.00 \mathrm{E}-0.3$ Displacement vectors तामागाम

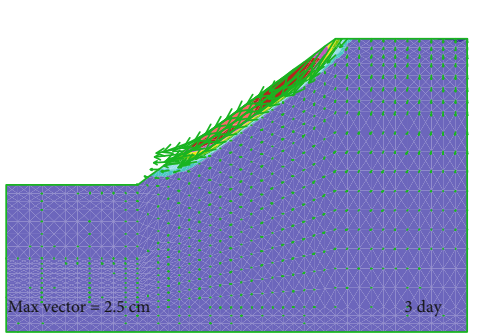

Step 46864

Flow time $2.5922 \mathrm{E}+05$

$-1.167 \mathrm{E}+00<x<2.217 \mathrm{E}+0$

$-5.667 \mathrm{E}+00<y<1.767 \mathrm{E}+0$

$X$-displacement conto

- $-2.00 \mathrm{E}-02$

$\mathbb{F}_{-1.50 \mathrm{E}-02}^{-1.75 \mathrm{E}-02}$

$-1.25 \mathrm{E}-02$
$-1.00 \mathrm{E}-02$
-

$-7.50 \mathrm{E}-03$
$-2.00 \mathrm{E}-03$
$-2.50 \mathrm{E}-03$

$-2.50 \mathrm{E}-03$
$-0.00 \mathrm{E}+00$

Contour interval $=2.50 \mathrm{E}-0$ max vector $=2519 \mathrm{E}-02$ ता 1 11

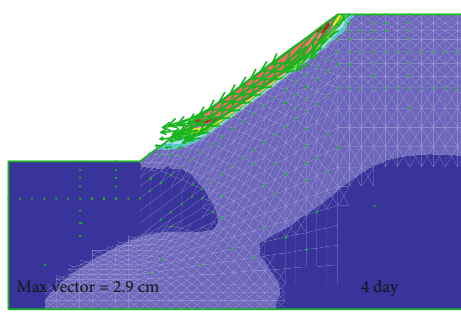

Step 46333

Flow time $3.4560 \mathrm{E}+05$

$1.167 \mathrm{E}+00<x<2.217 \mathrm{E}+01$

$-5.667 \mathrm{E}+00<y<1.767 \mathrm{E}+01$

$X$-displacement contours

$-2.00 \mathrm{E}-02$
$-1.75 \mathrm{E}-02$

$-1.50 \mathrm{E}-02$
-1.02

$-1.00 \mathrm{E}-02$
$-7.50 \mathrm{E}-03$
$-5.00 \mathrm{E}-03$

${ }_{-}^{-5.50 \mathrm{E}-03}$

Contour interval $=2.50$

max vector $=2.936 \mathrm{E}-02$

П11 1 1

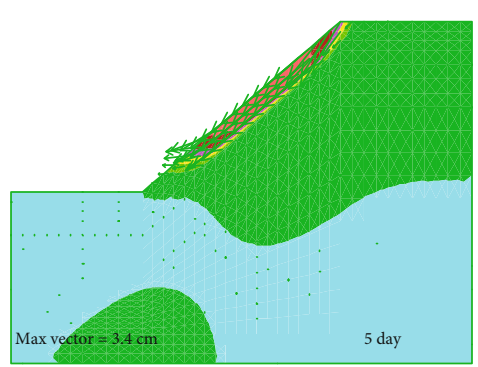

Step 48639

Flow time 4.3202E+05

$-1.167 \mathrm{E}+00<x<2.217 \mathrm{E}+0$ $-5.667 \mathrm{E}+00<y<1.767 \mathrm{E}+01$

$X$-displacement contours

H $-2.50 \mathrm{E}-02$

${ }_{-1.50 \mathrm{E}-02}^{-2.00 \mathrm{E}-02}$

- $-1.00 \mathrm{E}-02$

$-5.00 \mathrm{E}-03$

Contour interval $=5.00 \mathrm{E}-03$

Displacement vectors

max vector $=3.394 \mathrm{E}-02$

एगामापा

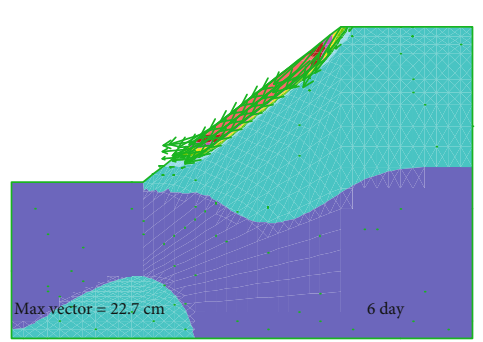

Step 54633

Flow time 5.1841E+05

$-1.167 \mathrm{E}+00<x<2.217 \mathrm{E}+01$

$-5.667 \mathrm{E}+00<y<1.767 \mathrm{E}+01$

$X$-displacement contours

$F^{-1.75 \mathrm{E}-01}$

$-1.25 \mathrm{E}-01$

$-7.50 \mathrm{E}-02$

$-2.50 \mathrm{E}-02$

Contour interval $=2.50 \mathrm{E}-02$

Displacement vectors

$\max$ vector $=2.273 \mathrm{E}$ ${ }_{0}^{1} 11 T_{5 \mathrm{E}-1}$

(a) Without support

Figure 5: Continued. 

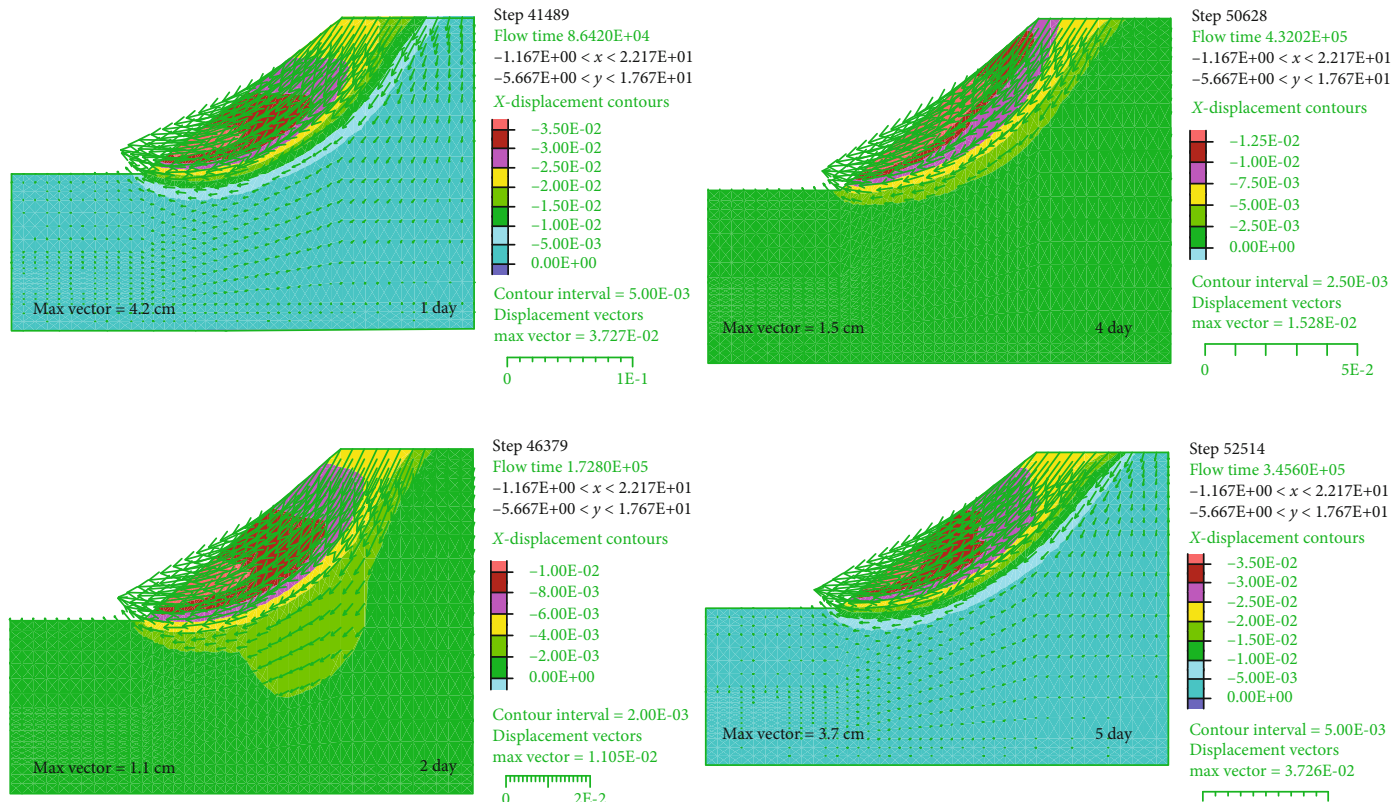

Step 52514

Hlow time $3.4560 \mathrm{E}+05$

$-1.167 \mathrm{E}+00<x<2.217 \mathrm{E}+01$ $-5.667 \mathrm{E}+00<y<1.767 \mathrm{E}+01$ $X$-displacement contours
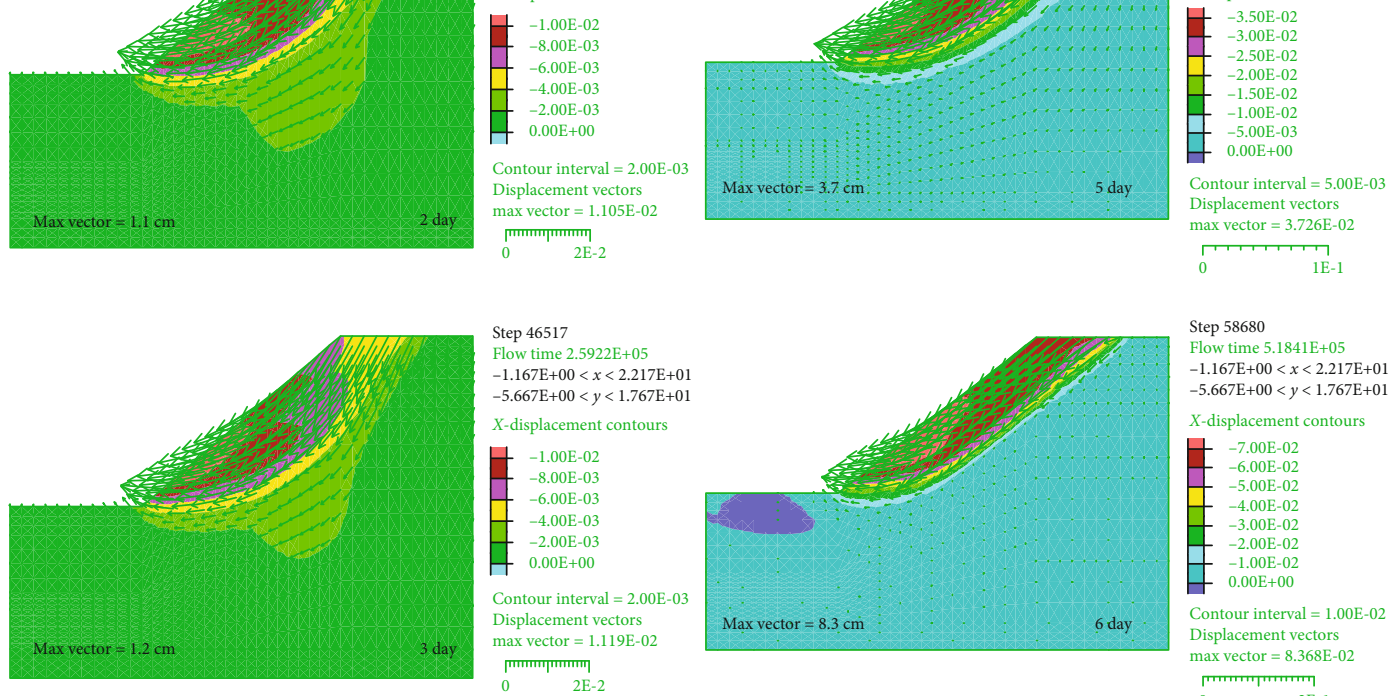

Step 58680

Flow time 5.1841E +05 列

$X$-displacement contours

H $-7.00 \mathrm{E}-02$

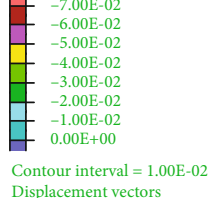

Contour interval $=1.00 \mathrm{E}$
Displacement vectors max vector $=8.368 \mathrm{E}-02$

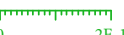

(b) With support

FigURE 5: Horizontal displacement and total displacement of plain soil and reinforced expansive soil cut slopes for different rainfall durations.

reinforced expansive soil cut slope, in the course of continuous rain for six days, are shown in Figures 3 and 4 . The potential slip surface of the unreinforced expansive soil cut slope is deep at the initial stage of the rainfall. After three days of continuous rainfall, the potential slip surface becomes shallow; its buried depth changes from $2.9 \mathrm{~m}$ to $0.6 \mathrm{~m}$. The safety factors also reduce significantly from the original 2.07 to 0.96 after six days of rainfall. As a result, shallow layer collapse occurs at the slope. However, the potential slip surface of the reinforced expansive soil cut slope changes to $2.4 \mathrm{~m}$ from $3.1 \mathrm{~m}$ during the 6-day rainfall period; the safety factors are all greater than 1.75.

The horizontal displacement variations of the slope caused by continuous rainfall are shown in Figure 5 . As the rainfall continues, the horizontal displacement of the cut slope soil increases continuously, and longer rainfall duration makes a greater rate of horizontal displacement increase. After continuous rainfall for 6 days, the horizontal displacement of the slope increases sharply, from $3.4 \mathrm{~cm}$ to $22.7 \mathrm{~cm}$. At this time, the shallow slippage causes the overall failure of the expansive soil cut slope, which is consistent with the results obtained from the previous safety factor.
It is found that geogrid reinforcement treatment reduces the maximum displacement of the expansive soil cut slope significantly. For example, after rainfall for three days, the maximum displacement of the plain soil slope is $2.5 \mathrm{~cm}$, while the maximum displacement of the reinforced slope is $1.2 \mathrm{~cm}$, lesser by about $50 \%$. It is worth noting that the maximum displacement of the plain soil slope occurs in the shallow surface, and the failure occurs at about $1 \mathrm{~m}$ depth. The maximum displacement of the reinforced slope soil does not appear in the shallow layer. Instead, it turns to the inside of the slope and reduces the maximum displacement vector significantly. This shows the transfer of the potential slip surface to the inside of the expansive soil slope because of the inhibition effect of the geogrid.

It should be noted that the maximum displacement of unreinforced expansive soil cut slope is greater than the displacements in the subsequent stages of the rainfall, during the initial stage of rainfall (at the beginning 1-2 days). This is because the potential slip surface appears inside the slope, with a large displacement, during the early stage of rainfall. As the rainfall duration increases, the water content of the soil increases, and the transient saturation zone appears in 

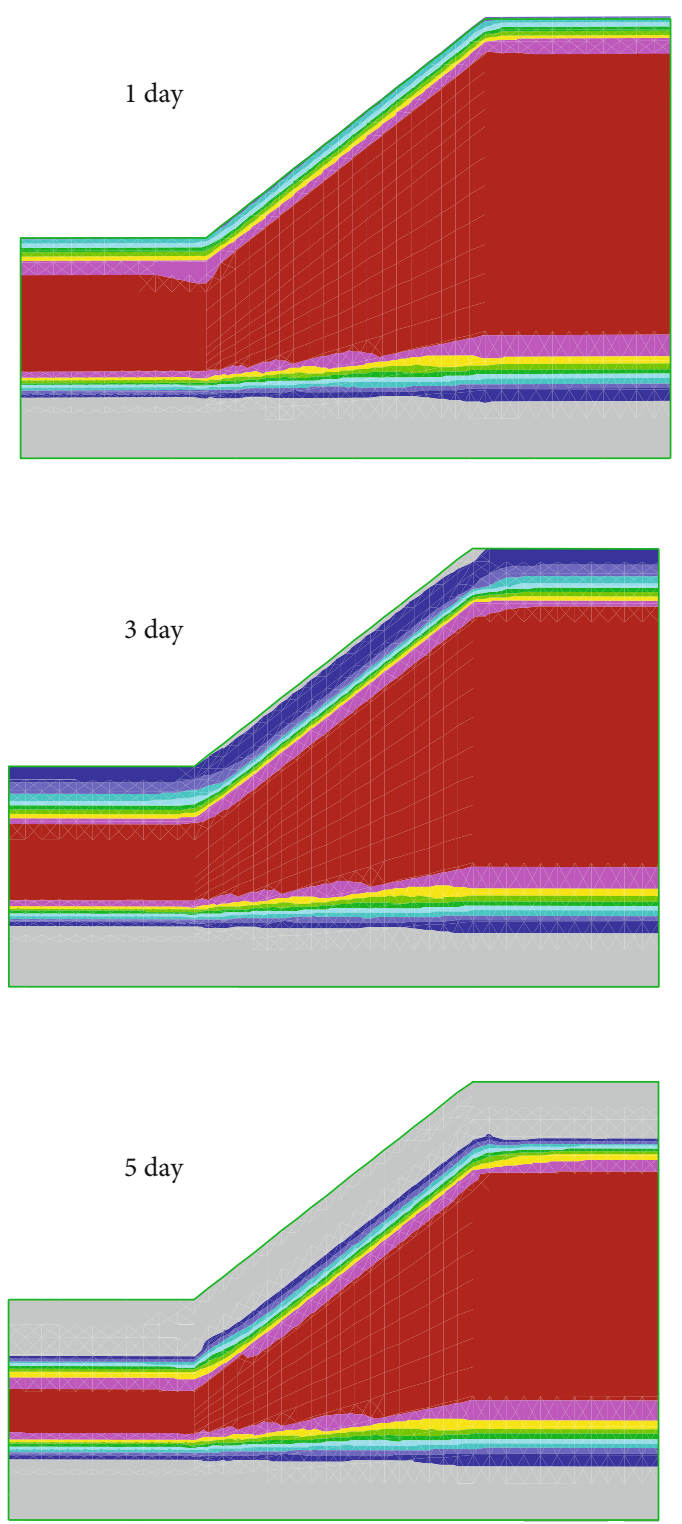

(a) Without support
Step 41489

Flow time $8.6420 \mathrm{E}+04$

$-1.167 \mathrm{E}+00<x<2.217 \mathrm{E}+01$

$-5.667 \mathrm{E}+00<y<1.767 \mathrm{E}+01$

Saturation contours

5.00E-01

6.00E-01

- $7.00 \mathrm{E}-01$

- $8.00 \mathrm{E}-01$

- $9.00 \mathrm{E}-01$

$1.00 \mathrm{E}+00$

Contour interval $=5.00 \mathrm{E}-02$

Flow vectors

* vectors of zero length *

Boundary plot

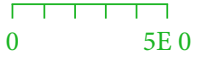

Step 46864

Flow time $2.5922 \mathrm{E}+05$

$-1.167 \mathrm{E}+00<x<2.217 \mathrm{E}+01$

$-5.667 \mathrm{E}+00<y<1.767 \mathrm{E}+01$

Saturation contours

$+5.00 \mathrm{E}-01$

6.00E-01

- 7.00E-01

8.00E-01

9.00E-01

$1.00 \mathrm{E}+00$

Contour interval $=5.00 \mathrm{E}-02$

Flow vectors

* vectors of zero length *

Boundary plot

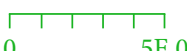

Step 54633

Flow time $5.1841 \mathrm{E}+05$

$-1.167 \mathrm{E}+00<x<2.217 \mathrm{E}+01$

$-5.667 \mathrm{E}+00<y<1.767 \mathrm{E}+01$

Saturation contours

- 5.00E-01

$6.00 \mathrm{E}-01$

$7.00 \mathrm{E}-01$

8.00E-01

$9.00 \mathrm{E}-01$

$1.00 \mathrm{E}+00$

Contour interval $=5.00 \mathrm{E}-02$

Flow vectors

* vectors of zero length *

Boundary plot

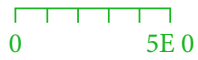

Figure 6: Continued. 


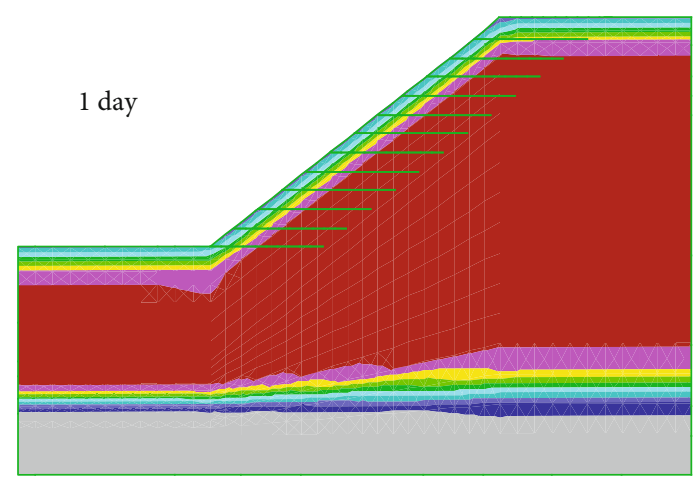

Step 41516

Flow time $8.6420 \mathrm{E}+04$

$-1.167 \mathrm{E}+00<x<2.217 \mathrm{E}+01$

$-5.667 \mathrm{E}+00<y<1.767 \mathrm{E}+01$

Saturation contours

- 5.00E-01

- 6.00E-01

- 7.00E-01

- $8.00 \mathrm{E}-01$

$1.00 \mathrm{E}+00$

Contour interval $=5.00 \mathrm{E}-02$

Flow vectors

* vectors of zero length *

Boundary plot
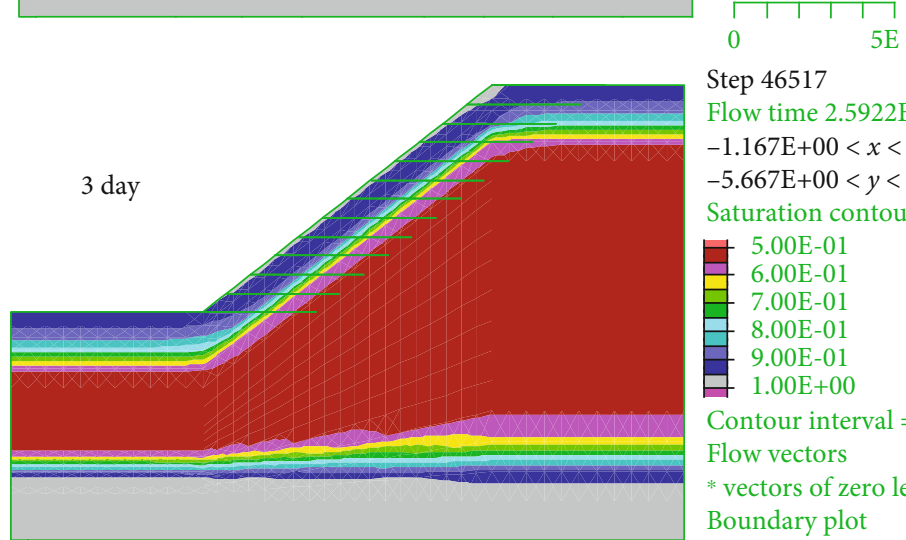

Step 46517

Flow time $2.5922 \mathrm{E}+05$

$-1.167 \mathrm{E}+00<x<2.217 \mathrm{E}+01$

$-5.667 \mathrm{E}+00<y<1.767 \mathrm{E}+01$

Saturation contours

- 5.00E-01

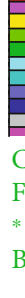

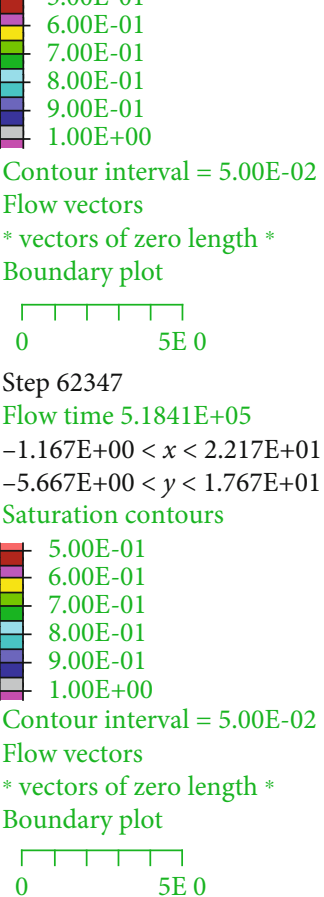

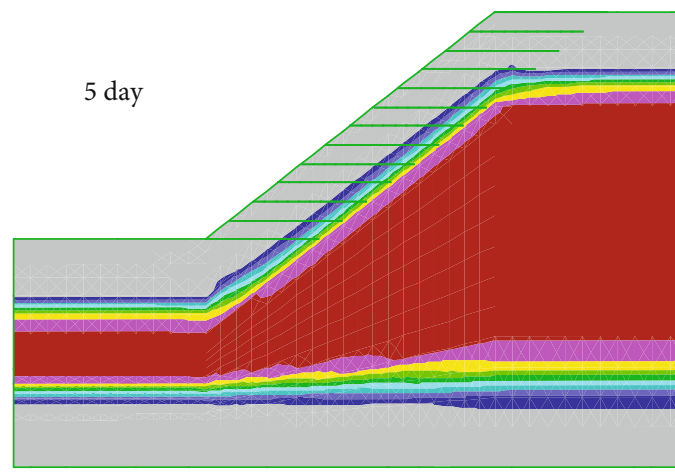

(b) With support

FIgURE 6: Seepage field distribution of plain soil and reinforced expansive soil cut slope for different rainfall durations.

the superficial layer of the slope. The matric suction decreases to 0 , and the soil strength becomes low, causing the potential slip surface of the slope to change gradually from deep sliding to shallow sliding damage. In contrast, the maximum displacement of the slope in the subsequent stage is relatively small. However, it grows with the increase in rainfall duration.

The changes of the seepage field on unreinforced and reinforced expansive soil slopes can be observed when the rainfall duration is one day, three days, and five days, respectively, to explore the effect of geogrid reinforcement on the seepage field distribution of expansive soil cut slope (see Figure 6).
The comparative analysis shows that there is no significant difference in the seepage field distribution between the two expansive soil slope models studied. It is believed that the geogrid reinforcement has a minute influence on the water migration and distribution in the slope. Also, a slope section is set at the foot of the slope (see Figure 7). The pore water press distribution is recorded to further explore the influence of geogrid reinforcement on the water migration of expansive soil slope. The result is presented in Figure 8 , where the $x$-coordinate is the distance to the vertex of the section.

It can be seen that the expansive soil has a large suction in the initial state and the surface soil reaches $-40 \mathrm{kPa}$. There is 


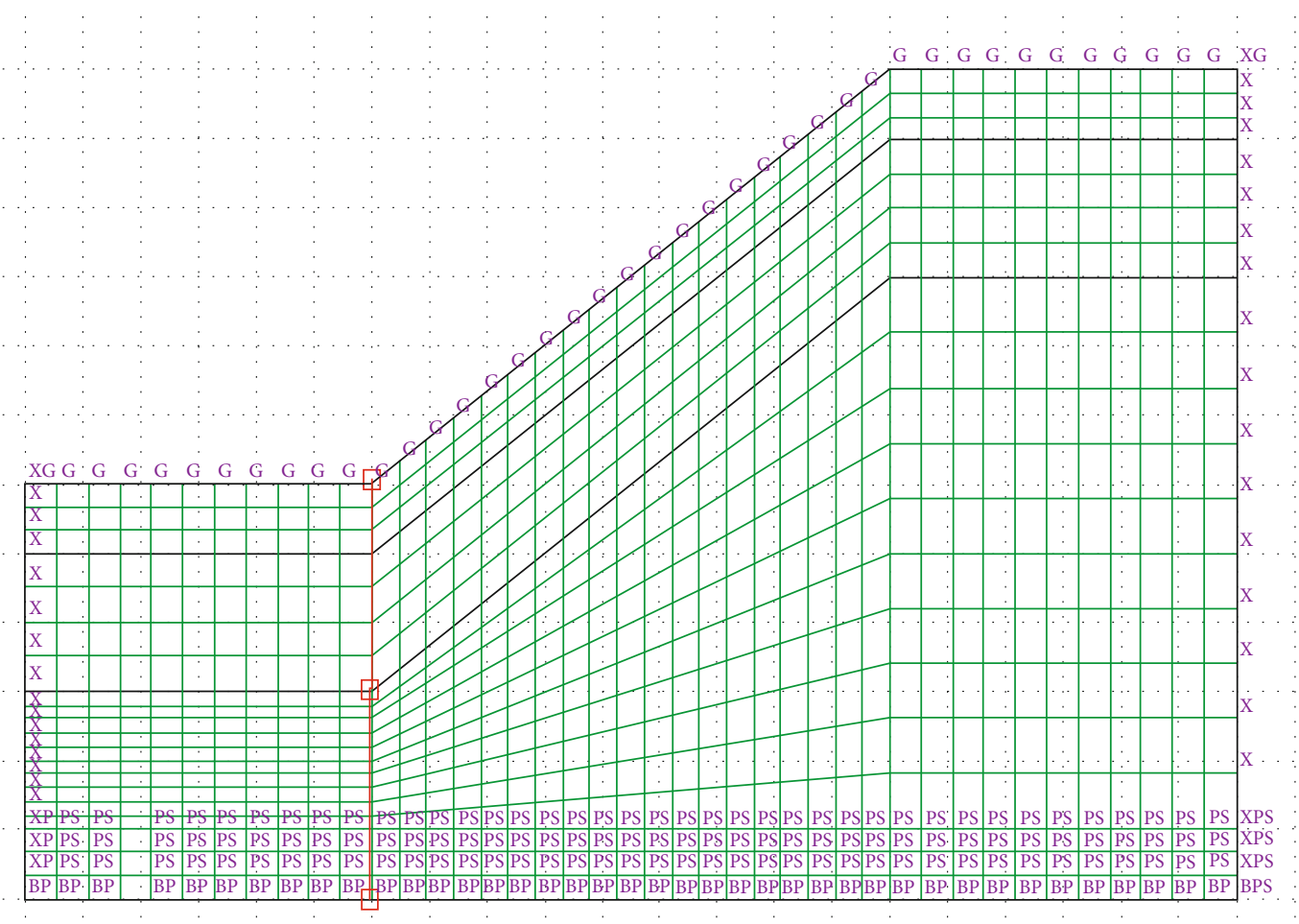

Figure 7: Slope section.

a saturation zone, of about $1 \mathrm{~m}$, at the bottom of the slope because of the influence of groundwater. As the rainfall duration increases, water gradually penetrates the soil, making the matrix suction of the surface soil decrease continuously. After five days of rainfall, a positive pore water press appears in the surface soil, which indicates that the strong weathered zone has reached its saturation. Compared to the unreinforced soil slopes, the pore press distribution of the reinforced slopes does not change much, and its distributive law is basically consistent with that of the unreinforced soil slope. This further indicates that the geogrid reinforcement has less impact on water migration and distribution in the expansive soil cut slope.

3.4. Optimization of the Geogrid Reinforcement Parameter. Geogrids play a vital role in maintaining the stability of reinforced expansive soil slopes. In order to further explore the influence of the reinforcement interval and the interaction between the geogrid and soil on the stress and strain of the reinforced slope soil, a numerical simulation has been conducted for the reinforced slope with a length of $3.5 \mathrm{~m}$, grid interval of $0.5 \mathrm{~m}$, and four kinds of reinforcement intervals $(0.25 \mathrm{~m}, 0.5 \mathrm{~m}, 0.75 \mathrm{~m}$, and $1.0 \mathrm{~m})$. Figures 9-12 show the geogrid's axial force distribution, the shear stress distribution of the slope, the variation of the geogrid's maximum axial force with the height, and the horizontal displacement distribution of the slope. It can be seen that the variations of the maximum axial force with the height for grids under different reinforced interval conditions are basically the same-they first increase and then decrease. A smaller reinforced interval

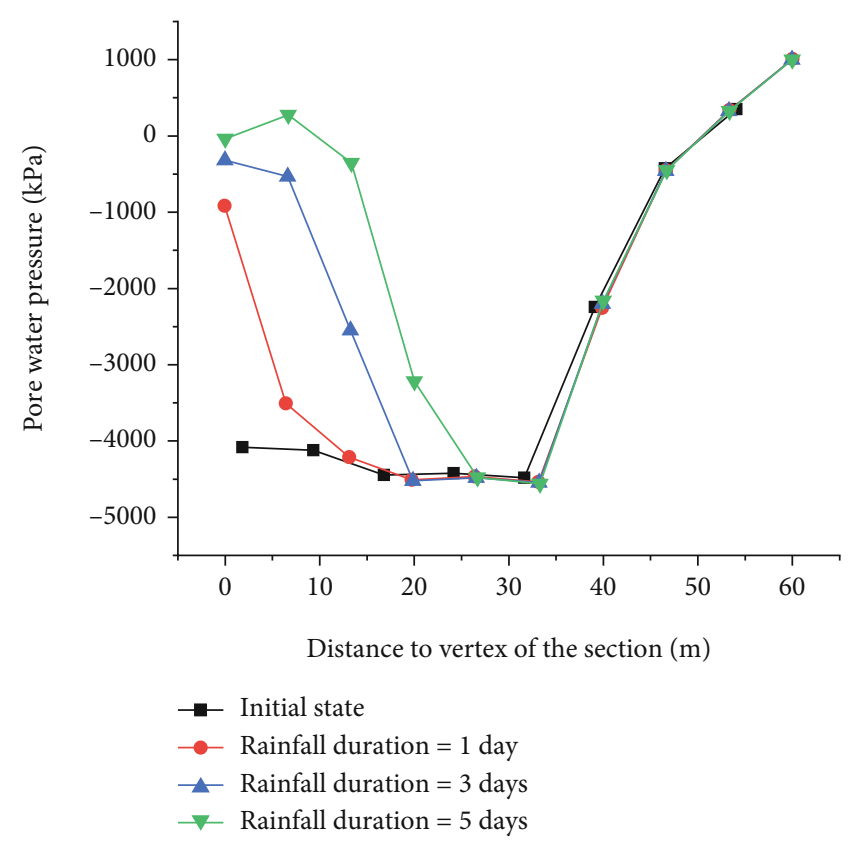

FIGURE 8: Distribution of pore pressure during different rainfall durations.

makes a smaller maximum value. For example, the maximum axial forces of four slope grids with the reinforced interval of $0.25 \mathrm{~m}, 0.5 \mathrm{~m}, 0.75 \mathrm{~m}$, and $1.0 \mathrm{~m}$ are $1.499 \mathrm{kN}$, $2.545 \mathrm{kN}, 3.235 \mathrm{kN}$, and $5.300 \mathrm{kN}$, respectively; the horizontal displacements of the slope increase first and then decrease 

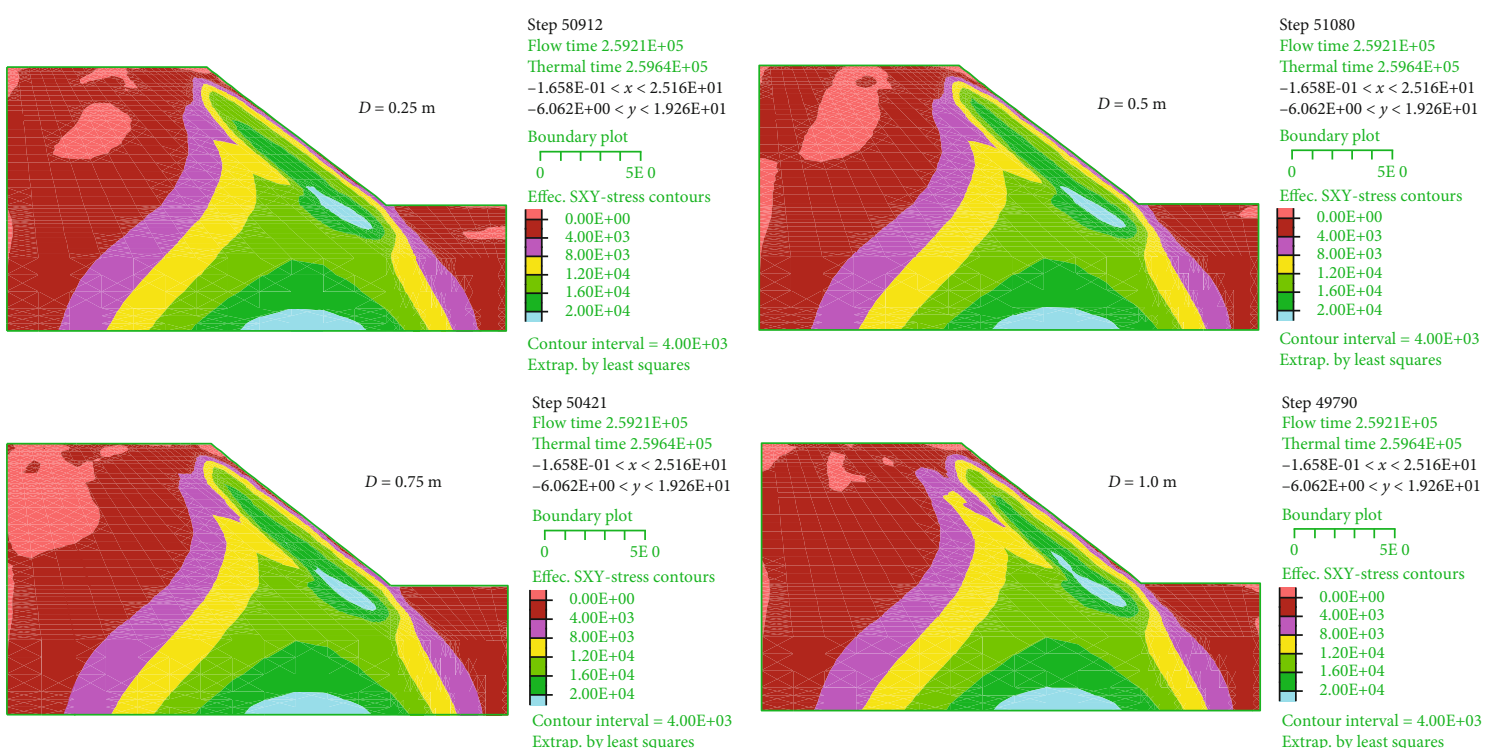

FiguRE 9: Shear stress distribution of slopes with different reinforced intervals $\left(\tau_{x y}\right)$.

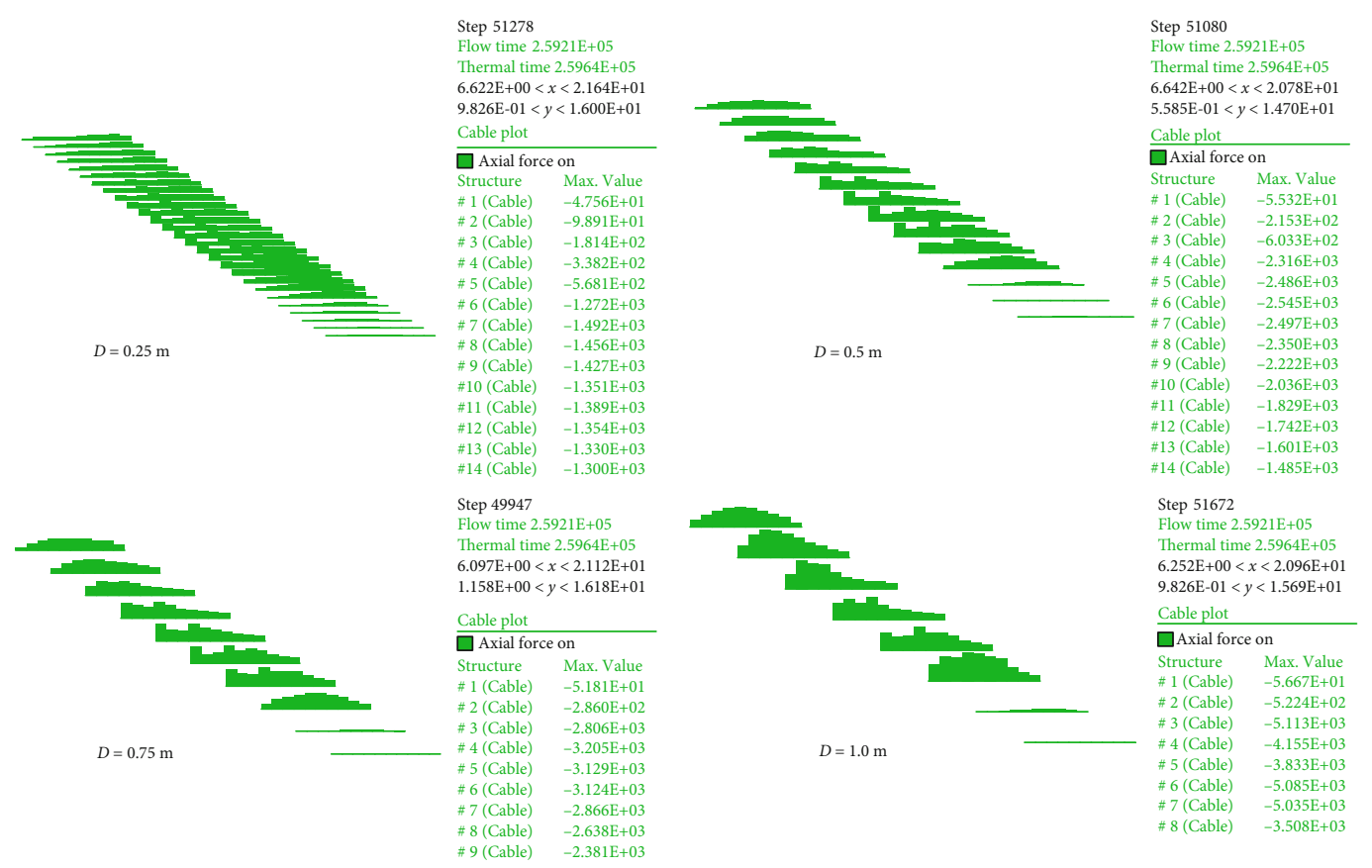

FIGURE 10: Axial force distribution of slopes with different reinforced intervals.

with the increase of height, and the value increases with larger reinforced interval. When the reinforced interval increases from $0.25 \mathrm{~m}$ to $0.75 \mathrm{~m}$, the displacement difference remains relatively stable; however, it varies greatly when the reinforced interval increases from $0.75 \mathrm{~m}$ to $1.0 \mathrm{~m}$. The maximum displacements can be $1.17 \mathrm{~m}, 1.80 \mathrm{~m}, 2.43 \mathrm{~m}$, and $4.75 \mathrm{~m}$, respectively. The safety factors decrease with the increase of reinforcement interval, which is 1.33, 1.17, 1.11 , and 1.06 , respectively.

The positions of the most dangerous sliding surfaces are basically the same, and the maximum shear strain increment of the shear surface decreases with the reinforcement interval. Therefore, the reinforcement interval has a great influence on the stability of the expansive soil slope, and a smaller interval makes better stability of the slope. The reasons are the following: smaller reinforcement interval makes more layers of the slope, and less thick reinforced soil makes less moisture absorption, expansion, and softening; the increased number of geogrids leads to less load-carrying and better integrity, thus enhancing the ability to limit the horizontal deformation of the slope. However, for actual engineering, the reinforcement interval should not be small. 


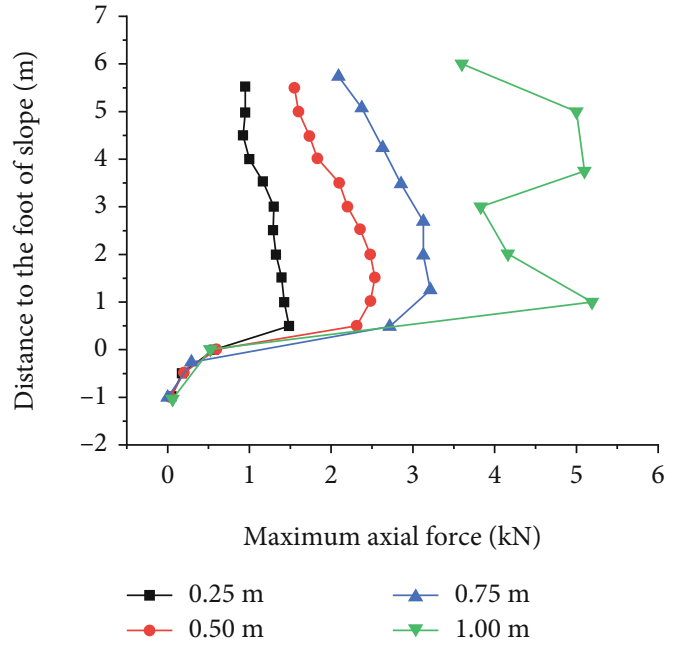

FIGURE 11: The distribution of the geogrid's max axial force with different reinforcement spacing.

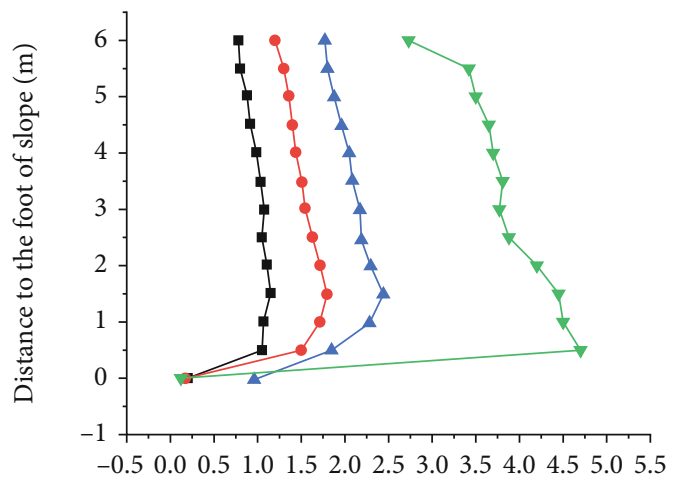

Horizontal displacement $(\mathrm{cm})$

$$
\begin{array}{ll}
\rightarrow 0.25 \mathrm{~m} & \rightarrow 0.75 \mathrm{~m} \\
\rightarrow-0.50 \mathrm{~m} & \rightarrow-00 \mathrm{~m}
\end{array}
$$

FIGURE 12: The distribution of horizontal displacement of the slope with different reinforcement spacing.

It should be determined depending upon the actual engineering conditions, construction operability, economics, and other factors.

\section{Conclusions}

(1) The nonlinear distribution law of strength, fitted by a generalized power function, has been obtained based on a series of shear strength tests of expansive soil, considering low stress and dry-wet cycles. The numerical model of the expansive soil slope, considering nonlinear strength and dry-wet cycles, has been constructed directly. The model is theoretically more reasonable than the conventional model; its simulation results are more in line with the engineering practice

(2) Analysis and evaluation have been conducted on the stability of an expansive soil slope in Nanning Outer
Ring Expressway, and the safety factor value and the depth of slip surface have been obtained under different rainfall and reinforcement conditions. The results can be used to provide references for the stability analysis of expansive soil slopes in hot and humid regions

(3) The reinforcement interval has a huge impact on the stability of the expansive soil slopes, and a smaller interval gives better stability to the slope. However, for actual engineering, the reinforcement interval should not be small. It should be determined depending on the actual engineering conditions, construction operability, economics, and other factors

(4) It should be noted that the use of commercial computer codes in this study has certain limitations. For example, the effect of chemical reactions on the shallow layer destruction of expansive soil slopes could not be considered. Additionally, the horizontal and vertical infinite extension of the soil mass cannot be simulated in the numerical model. These factors should be considered in future studies

\section{Data Availability}

All data included in this study are available upon request by contact with the corresponding author.

\section{Conflicts of Interest}

The authors declare no conflicts of interest.

\section{Acknowledgments}

This work was supported by the National Natural Science Foundation of China (Grant No. 51909150) and the Key Research \& Development Plan of Shandong Province (Grant No. 2019GSF111022).

\section{References}

[1] K. V. Ramana, "Humid tropical expansive soils of Trinidad: their geotechnical properties and areal distribution," Engineering Geology, vol. 34, no. 1-2, pp. 27-44, 1993.

[2] J. L. Zheng and H. P. Yang, Theory and Practice of Expansive Soil Treatment Technology, China Communication Press, Beijing, 2004.

[3] A. W. Bishop, D. L. Webb, and P. I. Lewin, "Undisturbed samples of London clay from the Ashford Common shaft: strength-effective stress relationships," Geotechnique, vol. 15, no. 1, pp. 1-31, 1965.

[4] T. S. Hou, G. L. Xu, Y. J. Shen, Z. Z. Wu, N. N. Zhang, and R. Wang, "Formation mechanism and stability analysis of the Houba expansive soil landslide," Engineering Geology, vol. 161, pp. 34-43, 2013.

[5] R. W. Day and G. W. Axten, "Surficial stability of compacted clay slopes," Journal of Geotechnical Engineering, vol. 115, no. 4, pp. 577-580, 1989.

[6] M. Maksimovic, "Nonlinear failure envelope for soils," Journal of Geotechnical Engineering, vol. 115, no. 4, pp. 581-586, 1989. 
[7] P. He, S.-c. Li, J. Xiao, Q.-q. Zhang, F. Xu, and J. Zhang, "Shallow sliding failure prediction model of expansive soil slope based on Gaussian process theory and its engineering application," KSCE Journal of Civil Engineering, vol. 22, no. 5, pp. 1709-1719, 2017.

[8] S. K. Mohammad, H. Sahadat, A. Asif, and F. Mohammad, "Investigation of a shallow slope failure on expansive clay in Texas," Engineering Geology, vol. 219, pp. 118-129, 2017.

[9] S. E. Cho and S. R. Lee, "Instability of unsaturated soil slopes due to infiltration," Computers and Geotechnics, vol. 28, no. 3, pp. 185-208, 2001.

[10] E. E. Alonso, A. Gens, and C. H. Delahaye, "Influence of rainfall on the deformation and stability of a slope in overconsolidated clays: a case study," Hydrogeology Journal, vol. 11, no. 1, pp. 174-192, 2003.

[11] W. Ehlers, T. Graf, and M. Ammann, "Deformation and localization analysis of partially saturated soil," Computer Methods in Applied Mechanics and Engineering, vol. 193, no. 27, pp. 885-910, 2004.

[12] L. L. Zhang, L. M. Zhang, and W. H. Tang, "Rainfall-induced slope failure considering variability of soil properties," Geotechnique, vol. 55, no. 2, pp. 183-188, 2005.

[13] R. H. Chen, H. P. Chen, K. S. Chen, and H. B. Zhung, "Simulation of a slope failure induced by rainfall infiltration," Environmental Geology, vol. 58, no. 5, pp. 943-952, 2009.

[14] J. Zhang, N. Little Dallas, N. Hariharana, and Y. R. Kim, "Prediction of climate specific vertical movement of pavements with expansive soils based on long-term 2D numerical simulation of rainwater infiltration," Computers and Geotechnics, vol. 115, p. 103172, 2019.

[15] A. S. Ai-Homoud, H. Khoury, and Y. A. Al-Omari, "Mineralogical and engineering properties of problematic expansive clayey beds causing landslides," Bulletin of the International Association of Engineering Geology, vol. 54, no. 1, pp. 13-31, 1996.

[16] C. Meisina, "Swelling-shrinking properties of weathered clayey soils associated with shallow landslides," Quarterly Journal of Engineering Geology \& Hydrogeology, vol. 37, no. 2, pp. 7794, 2004.

[17] Z. Z. Yin, J. Wei, and J. P. Yuan, "Mechanism of slope slide of expansive soil and reinforcement for the slope," Journal of Hydraulic Engineering, vol. 41, no. 1, pp. 1-6, 2010.

[18] H. Rahardjo, X. W. Li, D. G. Toll, and E. C. Leong, "Effect of antecedent rainfall on slope stability," Geotechnical and Geological Engineering, vol. 19, no. 3/4, pp. 371-399, 2001.

[19] A. Rahimi, H. Rahardjo, and E. Leong, "Effect of antecedent rainfall patterns on rainfallinduced slope failure," Journal of Geotechnical and Geoenviromental Engineering, vol. 137, no. 5, pp. 483-491, 2010.

[20] S. C. Qi and S. K. Vanapalli, "Hydro-mechanical coupling effect on surficial layer stability of unsaturated expansive soil slopes," Computers and Geotechnics, vol. 70, pp. 68-82, 2015.

[21] B. E. Hobbs and A. Ord, "Analytical solutions of nonaqueousphase-liquid dissolution problems associated with radial flow in fluid-saturated porous media," Journal of Hydrology, vol. 494, pp. 96-106, 2013.

[22] S. Peng, B. Hobbs, and A. Ord, "Effects of mineral dissolution ratios on chemical-dissolution front instability in fluidsaturated porous media," Transport in Porous Media, vol. 82, pp. 317-335, 2010.
[23] B. E. Hobbs, K. Regenauer-Lieb, and A. Ord, "Computational simulation for the morphological evolution of nonaqueous phase liquid dissolution fronts in two-dimensional fluidsaturated porous media," Computational Geosciences, vol. 15, pp. 167-183, 2011.

[24] T. Poulet and K. Regenauer-Lieb, "Numerical modeling of toxic nonaqueous phase liquid removal from contaminated groundwater systems: mesh effect and discretization error estimation," International Journal for Numerical and Analytical Methods in Geomechanics, vol. 39, pp. 571-593, 2015.

[25] R. Raid, J. Al-Omari, and H. Faris, "Swelling resistant geogrida new approach for the treatment of expansive soils," Geotextiles and Geomembranes, vol. 10, no. 4, pp. 295-317, 1991.

[26] S. M. Hejazi, M. Sheikhzadeh, S. M. Abtahi, and A. Zadhoush, "A simple review of soil reinforcement by using natural and synthetic fibers," Construction and Building Materials, vol. 30, pp. 100-116, 2012.

[27] L. R. Xu, J. M. Ling, and B. C. Liu, "Experiment on interface friction coefficient parameters between geogrids and expansive soils," Tong Ji University, vol. 32, no. 2, pp. 172-176, 2004.

[28] H. P. Yang, Y. X. Qu, and J. L. Zheng, "New advances in the research of Ningming expansive soil," Geotechnical Engineering Journal, vol. 21, no. 9, pp. 981-987, 2005.

[29] J. R. Zou, T. Y. Liu, and W. M. Leng, “The model test research on interaction of soil and geogrid," Journal of Railway Science and Engineering, vol. 3, pp. 51-55, 2005.

[30] J. L. Zheng and H. P. Yang, Expansive Soil Engineering of Highway, China Communication Press, Beijing, 2009.

[31] J. Xiao, H. P. Yang, and X. Z. Wang, "Analysis of nonlinear characteristics of shear strength of Nanning expansive soil and its influencing factors," China Journal of Highway and Transport, vol. 27, no. 10, pp. 2-7, 2014.

[32] H. P. Yang, X. Z. Wang, and J. Xiao, "Influence of wettingdrying cycles on strength characteristics of Nanning expansive soils," Chinese Journal of Geotechnical Engineering, vol. 36, no. 5, pp. 950-954, 2014.

[33] Y. Ping, M. Z. Liu, and S. H. Zheng, "Stability analysis of expansive soil slope with rainfall infiltration," Chinese Journal of Rock Mechanics and Engineering, vol. 23, no. 1, pp. 44784484, 2004.

[34] W. T. Zhan, J. Xiao, G. Y. Chen, and J. Chang, "Numerical simulation of seepage and stability analysis of expansive soil slope," Industrial Construction, vol. 48, no. 9, pp. 133-139, 2018. 